\title{
Five new species of the genus Singularia Arenberger, 1988 (Lepidoptera, Pterophoridae)
}

\author{
Vasiliy KOVTUNOVICH ${ }^{1}$, Peter USTJUZHANIN ${ }^{2}$, Mildred MARQUEZ ${ }^{3}$ \& \\ Anna USTJUZHANINA ${ }^{4, *}$ \\ ${ }^{1}$ Moscow Society of Nature Explorers, \\ c/o Malaya Filevskaya str., 24/1, app. 20, 121433, Russia. \\ ${ }^{2}$ Altai State University, Lenina 61, Barnaul, 656049, Russia. \\ ${ }^{3}$ National Autonomous University of Honduras, Siguatepeque, Comayagua, Honduras. \\ ${ }^{4}$ National Research Tomsk Polytechnic University, Lenina 30, Tomsk, 634050, Russia. \\ ${ }^{1}$ E-mail: vasko-69@mail.ru \\ ${ }^{2}$ E-mail: petrust@mail.ru \\ ${ }_{3}^{3}$ E-mail: mildredpmarquez@gmail.com \\ * Corresponding author: uak@tpu.ru \\ ${ }^{1}$ urn:1sid:zoobank.org:author:1959492D-B1A5-45F7-9C11-F079D399B42B \\ ${ }^{2}$ urn:lsid:zoobank.org:author:60F67CCF-F6C9-4CD4-A2DF-F3216DC46958 \\ ${ }^{3}$ urn:1sid:zoobank.org:author:6D2884AB-DE79-4454-9E20-D3D83DB1FAAA \\ ${ }^{4}$ urn:lsid:zoobank.org:author:4A20CB2F-2FA9-4FB6-9983-82E203FFB0E1
}

\begin{abstract}
Expeditions of Ron Brechlin, Viktor Synjaev, Mildred Márquez, Juan Machado, Oleg Romanov and other colleagues over the last five years in Colombia, Ecuador and Bolivia have resulted in significant collections of Pterophoridae Zeller, 1841. The article describes five new species: Singularia brechlini Kovtunovich \& Ustjuzhanin sp. nov., Singularia sinjaevi Kovtunovich \& Ustjuzhanin sp. nov., Singularia guajiro Kovtunovich \& Ustjuzhanin sp. nov., Singularia tolima Kovtunovich \& Ustjuzhanin sp. nov. and Singularia lesya Kovtunovich \& Ustjuzhanin sp. nov.
\end{abstract}

Keywords. Lepidoptera, Pterophoridae, Singularia, new species, Colombia, Ecuador, Bolivia.

Kovtunovich V., Ustjuzhanin P., Marquez M. \& Ustjuzhanina A. 2016. Five new species of the genus Singularia Arenberger, 1988 (Lepidoptera, Pterophoridae). European Journal of Taxonomy 247: 1-11. http://dx.doi. org/10.5852/ejt.2016.247

\section{Introduction}

Alucita walsinghami Fernald, 1898 was described in a different genus, Singularia Arenberger, 1988. Later, Gielis \& Matthews (1994) described the genus Chocophorus and included in it three known species and two new for science: Aciptilia alternaria Zeller, 1874, Pterophorus carabayus Arenberger, 1990, Alucita leptochorda Meyrick, 1913, Chocophorus solisi Gielis \& Matthews, 1994 and Chocophorus venedictoffi Gielis \& Matthews, 1994. In a subsequent publication, Gielis (2011) described one more 
species, Chocophorus mayaensis Gielis, 2011. Gielis (2012) synonymized Chocophorus under the genus Singularia.

The genus Singularia, widespread in South and Central America, comprises 12 species, including those described in the present paper: Singularia alternaria (Zeller, 1874), Singularia carabayus (Arenberger, 1990), Singularia leptochorda (Meyrick, 1913), Singularia mayaensis (Gielis, 2011), Singularia solisi (Gielis \& Matthews, 1994), Singularia venedictoffi (Gielis \& Matthews, 1994), and Singularia walsinghami (Fernald, 1898). The species of this genus mainly inhabit mountain forests.

\section{Material and methods}

Holotypes and paratypes of the species described are stored in the collections listed below. Preparation of genitalia is necessary for the identification of Pterophoridae Zeller, 1841. Dissections were performed using standard methods.

\section{Institutional abbreviations}

BMNH $=$ Natural History Museum, London, U.K.

CUK = Research collection of P. Ustjuzhanin and V. Kovtunovich, Novosibirsk and Moscow, Russia

ZISP $\quad=$ Zoological Institute, St. Petersburg, Russia

ZMHB = Zoologisches Museum der Humboldt Universität, Berlin, Germany

\section{Results}

Class Hexapoda Blainville, 1816

Order Lepidoptera Linnaeus, 1758

Superfamily Pterophoroidea Kuznetsov \& Stekolnikov, 1979

Family Pterophoridae Zeller, 1841

Subfamily Pterophorinae Zeller, 1842

Tribe Pterophorini Bigot, Gibeaux, Nel \& Picard, 1998

Genus Singularia Arenberger, 1988

Singularia brechlini Kovtunovich \& Ustjuzhanin sp. nov.

urn:Isid:zoobank.org:act:EB77F98D-436D-4C7B-A75F-0F9FE26AA9F8

Figs $1-3$

\section{Diagnosis}

The male genitalia of Singularia brechlini Kovtunovich \& Ustjuzhanin sp. nov. resemble those of S. carabayus, but differ from them by rodlike anellus arms, which are wider and shorter in S. carabayus. The female genitalia of the new species are similar to those of $S$. alternaria in the shape of the antrum and signum, but differ by the shorter and more narrow antrum, and the wider signum.

\section{Etymology}

The species is named after the prominent German entomologist Dr. Ronald Brechlin, specialist in Saturniidae and Sphingidae, organizer and member of the expeditions during which this species was collected. 


\section{Material examined}

\section{Holotype}

COLOMBIA: $\hat{\jmath}$, adult, Valle del Cauca, Res. Forest La Albania, $3^{\circ} 57^{\prime} \mathrm{N}, 76^{\circ} 23^{\prime} \mathrm{W}, 1640 \mathrm{~m}$, 2-5 Nov. 2013, V. Synjaev \& M. Márquez leg. (ZISP 1836).

\section{Paratypes}

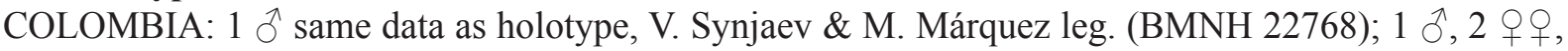

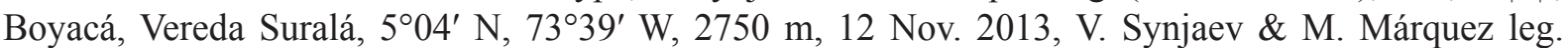

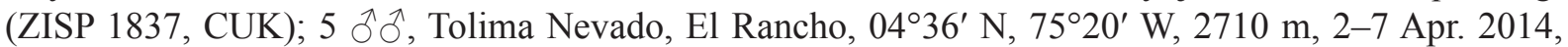
V. Synjaev, M. Márquez \& J. Machado leg. (CUK); 1 đo, Tolima Vereda El Campanario, 04²6' N, 75³4’ W, 3600 m, 29-31 Mar. 2014, V. Synjaev, M. Márquez \& J. Machado leg. (CUK).

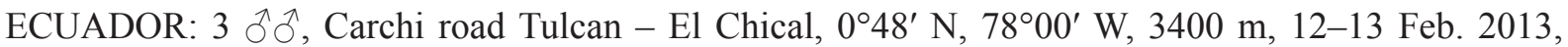
V. Synjaev \& O. Romanov leg. (BMNH 22769, ZMHB 201603, ZMHB 201604); 7 $\widehat{\jmath}$, Napo Prov., Papallacta, Rio San Pedro, $0^{\circ} 22^{\prime}$ S, $78^{\circ} 07^{\prime}$ W, 10 m, 18 Jan. 2012, R. Brechlin \& V. Synjaev leg.

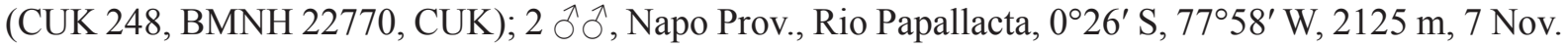
2011, R. Brechlin \& V. Synjaev leg. (CUK); $10^{\top}$, Carchi Prov., El Angel Ecological Reserve, 046’ N, 7803' W, 2786 m, 9-11 Nov. 2012, R. Brechlin \& V. Synjaev leg. (CUK).

\section{Description}

EXTERNAL CHARACTERS. Wingspan of holotype $19 \mathrm{~mm}$ and paratypes 19-23 mm. Head covered with grey setae, thorax brown with pale longitudinal stripes. Labial palps short, straight, pointed at tip, half eye diameter. Fore wings with spotted pattern. Portions of pale spots traced on brown-grey background at
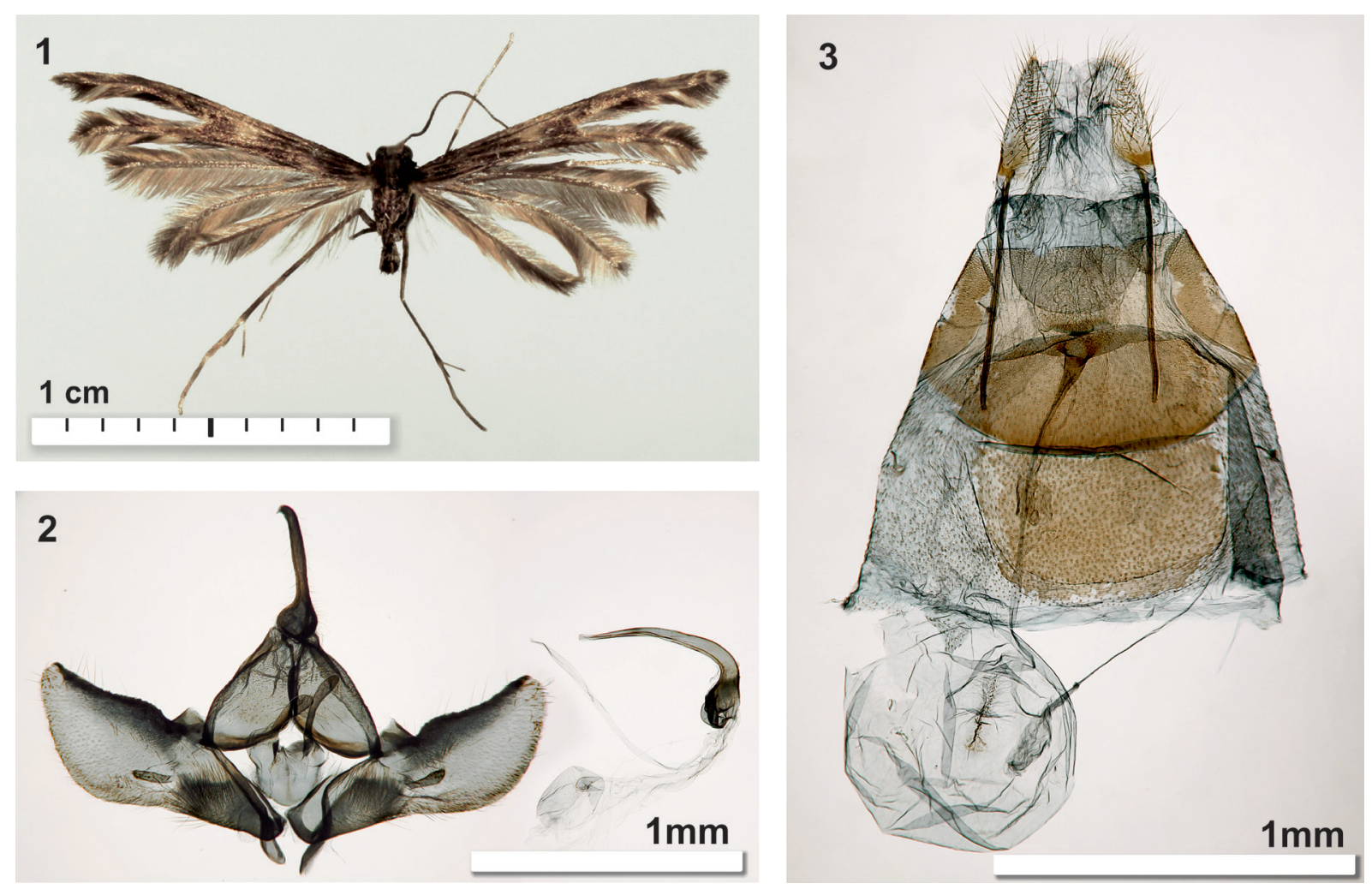

Figs 1-3. Singularia brechlini Kovtunovich \& Ustjuzhanin sp. nov. 1. Holotype (ZISP 1836). 2. Holotype, genitalia (ZISP 1836). 3. Paratype,, , genitalia (CUK 247). 
wing base, in central part and at cleft base. Fringe inside cleft dark grey, noticeably lightened only at base. Hind wings and fringe unicolorous ash-grey. Legs mottled brown with lightened portions.

MaLe Genitalia. Valves symmetric, strongly widened in middle part and narrowed in apical part. Small finger-like processes in basal part of both valves. Anellus arms rod-like, slightly widened at apices. Saccus wide, horseshoe-like. Uncus narrow, long, strongly tapered and bent at apex. Phallus thin, slightly concave, equal to uncus in length.

Female genitalia. Papillae anales oval. Apophyses posteriores thin, long. Apophyses anteriores not developed. Antrum short, in shape of narrow funnel. Ductus bursae narrow and long, poorly sclerotized. Bursa copulatrix round, signum fusiform.

\section{Distribution}

Ecuador, Colombia.

\section{Flight period}

January, April, March, November.

Singularia sinjaevi Kovtunovich \& Ustjuzhanin sp. nov. urn:1sid:zoobank.org:act:E6BC1817-2B31-42C7-821A-D817D56CD206

Figs $4-5$

\section{Diagnosis}

The male genitalia of Singularia sinjaevi Kovtunovich \& Ustjuzhanin sp. nov. resemble those of S. walsinghami, but differ from them by the narrow, long rod-like anellus arms whereas those of $S$. walsinghami are shorter and angulate. The phallus of the new species is strongly thickened and bent at a right angle in the basal part, whereas the phallus of $S$. walsinghami is almost straight.

\section{Etymology}

The species is named after Viktor Synjaev, the prominent Russian traveller and entomologist, who collected this species.
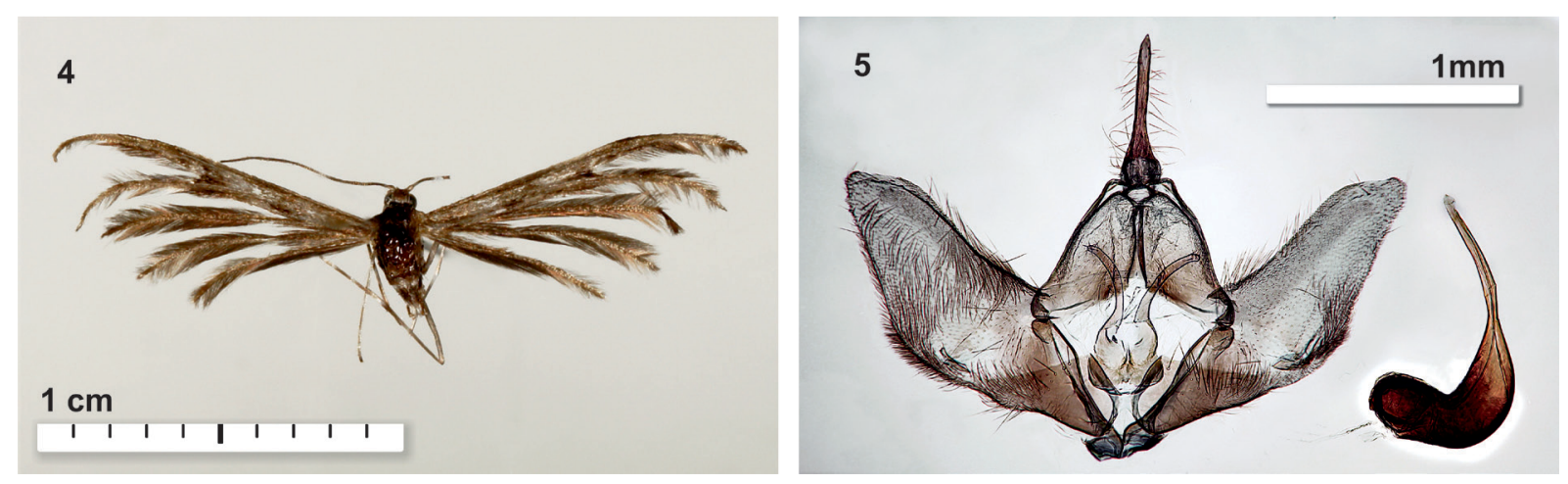

Figs 4-5. Singularia sinjaevi Kovtunovich \& Ustjuzhanin sp. nov. 4. Holotype (ZISP 1838). 5. Holotype, genitalia (ZISP 1838). 


\section{Material examined}

\section{Holotype}

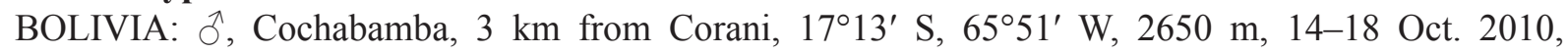
V. Synjaev \& O. Romanov leg. (ZISP 1838).

\section{Description}

\section{Male}

EXTERNAL CHARACTERS. Wingspan of holotype $19 \mathrm{~mm}$. Head, thorax and tegulae grey. Labial palps very short, 2.5 times shorter than eye diameter. Fore wings ash-grey. Small black spot at cleft base. Fringe inside cleft dark grey, slightly lightened only at base. Hind wings and fringe unicolorous ash-grey. Legs mottled brown with pale portions.

Male genitalia. Valves symmetric, rather wide, smoothly narrowed in distal part. Anellus arms long, rod-like, slightly concave. Uncus narrow, long, tapered at apex. Phallus rather short, strongly thickened, bent at right angle in basal part, in distal part significantly narrowed, equal to uncus in length.

\section{Female}

Unknown.

\section{Distribution}

Bolivia.

\section{Flight period}

October.

Singularia guajiro Kovtunovich \& Ustjuzhanin sp. nov. urn:1sid:zoobank.org:act:81C3A982-DE9D-4539-BF93-8357370173A1

Figs 6-8

\section{Diagnosis}

The male genitalia of Singularia guajiro Kovtunovich \& Ustjuzhanin sp. nov. are similar to those of $S$. alternaria in the form of the valves, but differ from them in the wide uncus and the zigzag-shaped phallus. The female genitalia of the new species resemble those of $S$. brechlini sp. nov. in the long filiform signum, but differ from them by the structure of the antrum and the apophyses anteriores.

\section{Etymology}

The species is named after one of the indigenous peoples of Colombia, the Guajiro.

\section{Material examined}

\section{Holotype}

COLOMBIA: ${ }^{\lambda}$, Cundinamarca dept., Vereda La Concepción, Bosque La Guajira, 4²47' N, $75^{\circ} 46^{\prime}$ W, 2910 m, 8-12 Nov. 2014, V. Synjaev, M. Márquez \& J. Machado leg. (ZISP 1842).

\section{Paratype}

COLOMBIA: 1 q, Boyacá, Vereda Suralá, 504' N, 7339’ W, 2750 m, 12 Nov. 2013, V. Synjaev \& M. Márquez leg. (ZISP 1843). 


\section{Description}

EXternal CHARACTERs. Wingspan of holotype $21 \mathrm{~mm}$ and paratype $19 \mathrm{~mm}$. Head, thorax and tegulae with dark grey scales. Labial palps dark brown, rather short, half eye diameter. Fore wings browngrey with portions of pale spots at wing base and in central part. Fringe inside cleft dark brown with alternation of yellow portions. Hind wings and their fringe unicolorous grey. Legs pale brown.

MaLE Genitalia. Valves symmetric, smoothly narrowed in distal part. Anellus arms rather short, rod-like, left arm shorter than right one, right arm slightly concave. Uncus small, noticeably widened in distal part. Phallus rather long, equal to length of valve, zigzag-shaped in distal part, thickened in basal part. Process of sternum VIII narrow and long with oval notch at tip.

Female genitalia. Papillae anales narrow triangle. Apophyses posteriores thin, long, slightly widened and bent at apices. Apophyses anteriores narrow, short. Antrum short tubular, sinuously curved. Ductus thin, very long, poorly sclerotized. Bursa copulatrix oval, signum narrow long, filiform, covered with small spiculae throughout its length.
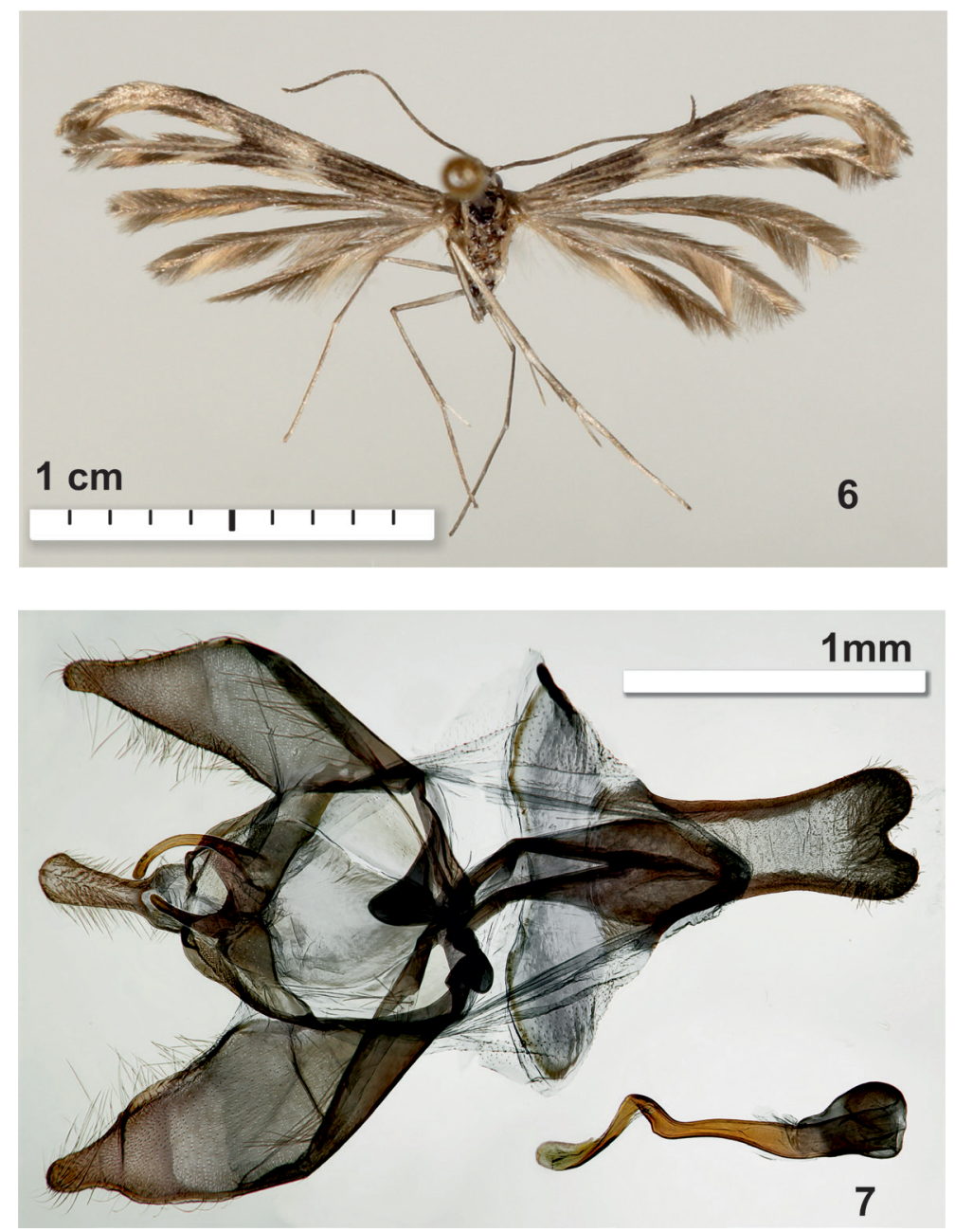

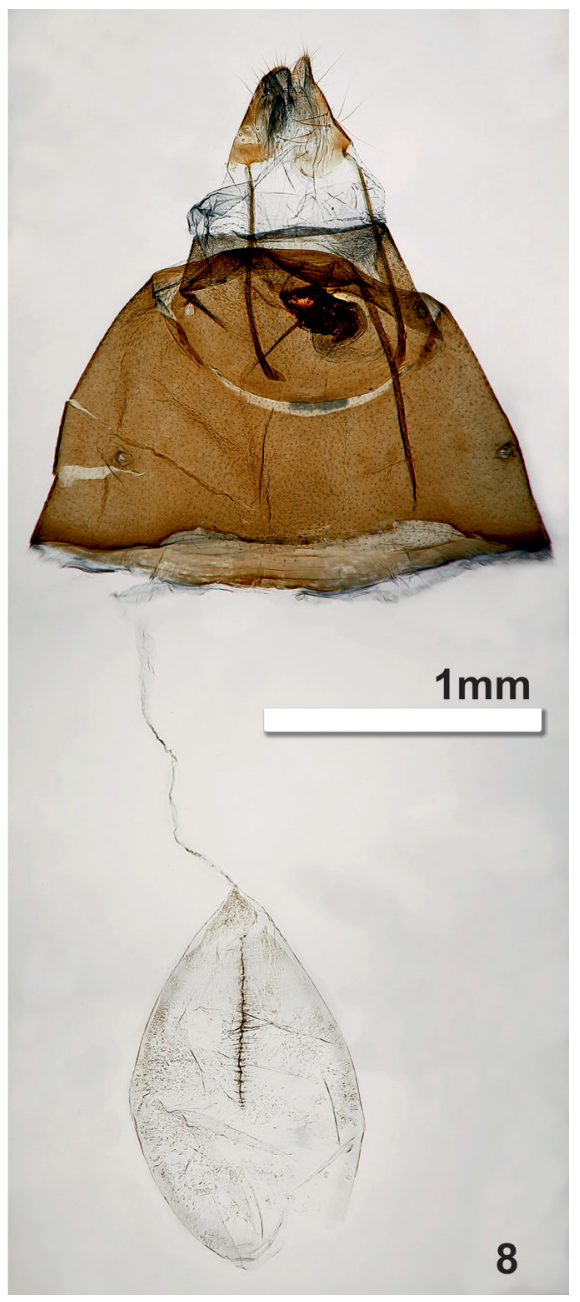

8

Figs 6-8. Singularia guajiro Kovtunovich \& Ustjuzhanin sp. nov. 6. Holotype (ZISP 1842). 7. Holotype, genitalia (ZISP 1842). 8. Paratype,, , genitalia (ZISP 1843). 


\section{Distribution}

Colombia.

\section{Flight period}

November.

Singularia tolima Kovtunovich \& Ustjuzhanin sp. nov.

urn:1sid:zoobank.org:act:7797B80E-5332-414D-8903-74BD1A80B1E0

Figs 9-10

\section{Diagnosis}

The male genitalia of Singularia tolima Kovtunovich \& Ustjuzhanin sp. nov. resemble to those of S. walsinghami in the short phallus and the tapered distal part, but differ from them by the asymmetric valves and the uncus, which is widened in the middle part.

\section{Etymology}

Toponymic name, after the state of Tolima where the new species has been collected.

\section{Material examined}

\section{Holotype}

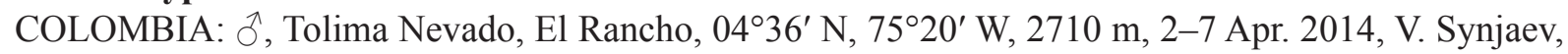
M. Márquez \& J. Machado leg. (ZISP 1839).

\section{Paratypes}

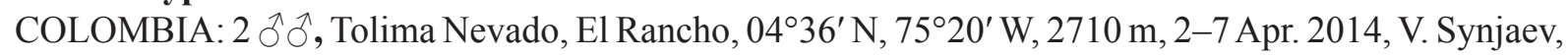

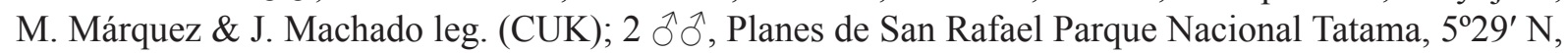
7600’ W, 2100 m, 18-21 Mar. 2015, V. Synjaev, M. Márquez \& J. Machado leg. (CUK).

\section{Description}

\section{Male}

EXTERNAL CHARACTERS. Wingspan of holotype $23 \mathrm{~mm}$ and paratypes $22-23 \mathrm{~mm}$. Head grey, thorax grey with white longitudinal stripes. Labial palps thin, rather long, slightly smaller than eye diameter. Fore wings with mottled pattern. Bright thin white stripes from wing base along streaks. Medial part of wing
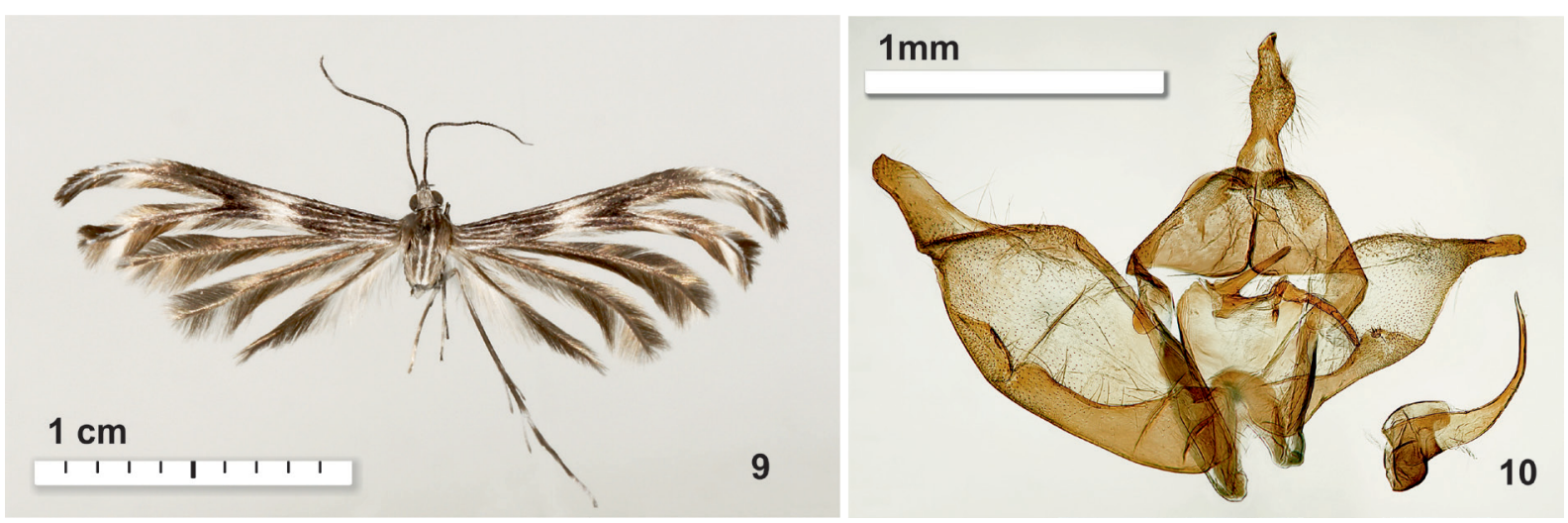

Figs 9-10. Singularia tolima Kovtunovich \& Ustjuzhanin sp. nov. 9. Holotype (ZISP 1839). 10. Holotype, genitalia (ZISP 1839). 
with bright white spot. First and second lobe from middle to apex brightly white. Fringe inside cleft dark grey with alternation of white portions. Hind wings ash-grey. Fringe of first lobe monochrome grey, second lobe with portion of white hairs in distal part, outer fringe of third lobe from base and further beyond the middle lightened with white hairs. Legs mottled brown with pale portions.

MaLe genitalia. Valves asymmetric, left one wider than right one. Distal part of both valves noticeably narrowed. No finger-like processes at valve bases. Anellus arms thin, of different lengths, left one two times shorter than right one. Saccus narrow with deep notch. Uncus strongly widened in middle part, tapered at apex. Phallus short, smoothly curved, thickened in basal part, tapered in distal part.

\section{Female}

Unknown.

\section{Distribution}

Colombia.

\section{Flight period}

April.

Singularia lesya Kovtunovich \& Ustjuzhanin sp. nov. urn:1sid:zoobank.org:act:83710892-5531-4A08-95EC-A74FB5F0F27E

Figs 11-13

\section{Diagnosis}

The male genitalia of Singularia lesya Kovtunovich \& Ustjuzhanin sp. nov. are similar to those of $S$. carabayus in the curved phallus, the arched saccus and the uncus, which is widened in the middle part and tapered at the apex. They are different in the strong saber outgrowths in the lower basal part of the sacculus, the rhomboid valves and the absence of finger-like processes at the valve bases. The female genitalia are distinguished by the absence of the signum and the broad lobe of the lamina postvaginalis in S. lesya sp. nov.

\section{Etymology}

The species in named after Olesya Snigur.

\section{Material examined}

\section{Holotype}

ECUADOR: 今̄, Carchi Prov., El Chical - Carolinae, 050’ N, 78¹3’ W, 2360 m, 20 Nov. 2012, R. Brechlin \& V. Synjaev leg. (ZISP 1840).

\section{Paratypes}

ECUADOR: $2 \hat{\jmath} \widehat{\partial}, 1$, same data as holotype (CUK); $3 \hat{\partial} \widehat{\partial}, 2 q+$, Pichincha, Camping Bella Vista, $0^{\circ} 00^{\prime} \mathrm{S}, 78^{\circ} 41^{\prime} \mathrm{W}, 2230 \mathrm{~m}, 1$ Dec. 2011, V. Synjaev \& O. Romanov leg. (ZISP 1841, CUK); 1 q, Planes de San Rafael Parque Nacional Tatama, 529' N, 76 $00^{\prime}$ W, 2100 m, 18-21 Mar. 2015, V. Synjaev,

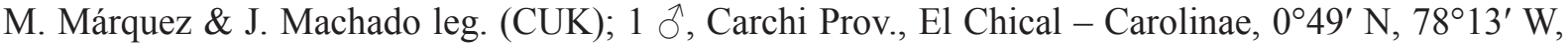
1970 m, 16 Dec. 2012, R. Brechlin \& V. Synjaev leg. (CUK); 1 +, Napo Prov., 6 km SE Cosanga, $0^{\circ} 37^{\prime}$ S, 7754' W, 2240 m, 22 Jan. 2012, R. Brechlin \& V. Synjaev leg. (ZMHB 201606); 1 ô, Pichincha, Camping Tambo Tanda, $0^{\circ} 01^{\prime}$ S, 78³8’ W, 1969 m, 25 Dec. 2011, V. Synjaev \& O. Romanov leg. (CUK); $10^{\lambda}$, Carchi Prov., El Chical -Carolinae, 049’ N, 78¹3’ W, 2150 m, 18 Nov. 2012, R. Brechlin \& 


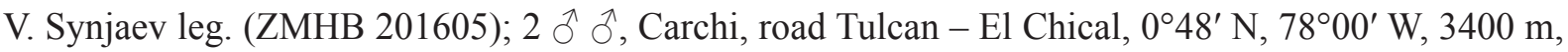
12-13 Feb. 2013, V. Synjaev \& O. Romanov leg. (CUK).

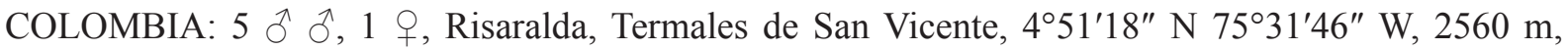
5-7 Nov. 2015, V. Synjaev \& J. Machado leg. (CUK 264, CUK 266, CUK).

\section{Description}

EXTERNAL CHARACTERS. Wingspan of holotype $18 \mathrm{~mm}$ and paratypes 16-22 $\mathrm{mm}$. Head pale grey, thorax brown with pale longitudinal stripes. Labial palps thin, long, equal to eye diameter. Fore wings with mottled pattern. Bright thin white stripes from wing base along streaks. Medial part of wing with bright white spot. First lobe from middle brightly white, on outer margin in apical part circled with distinct dark brown touch. Second lobe brown with white ending. Fringe inside cleft pale with mixture of grey hairs. Hind wings and fringe unicolorous grey. Legs pale brown.

Male genitalia. Valves symmetric, rhomboid. Strong saber outgrowths from lower basal area of sacculus. No finger-like processes in valves base. Uncus short, slightly bent. Anellus arms of different lengths, left one two times shorter than right one. Saccus arcuate. Phallus thin, arcuate, thickened in basal part.
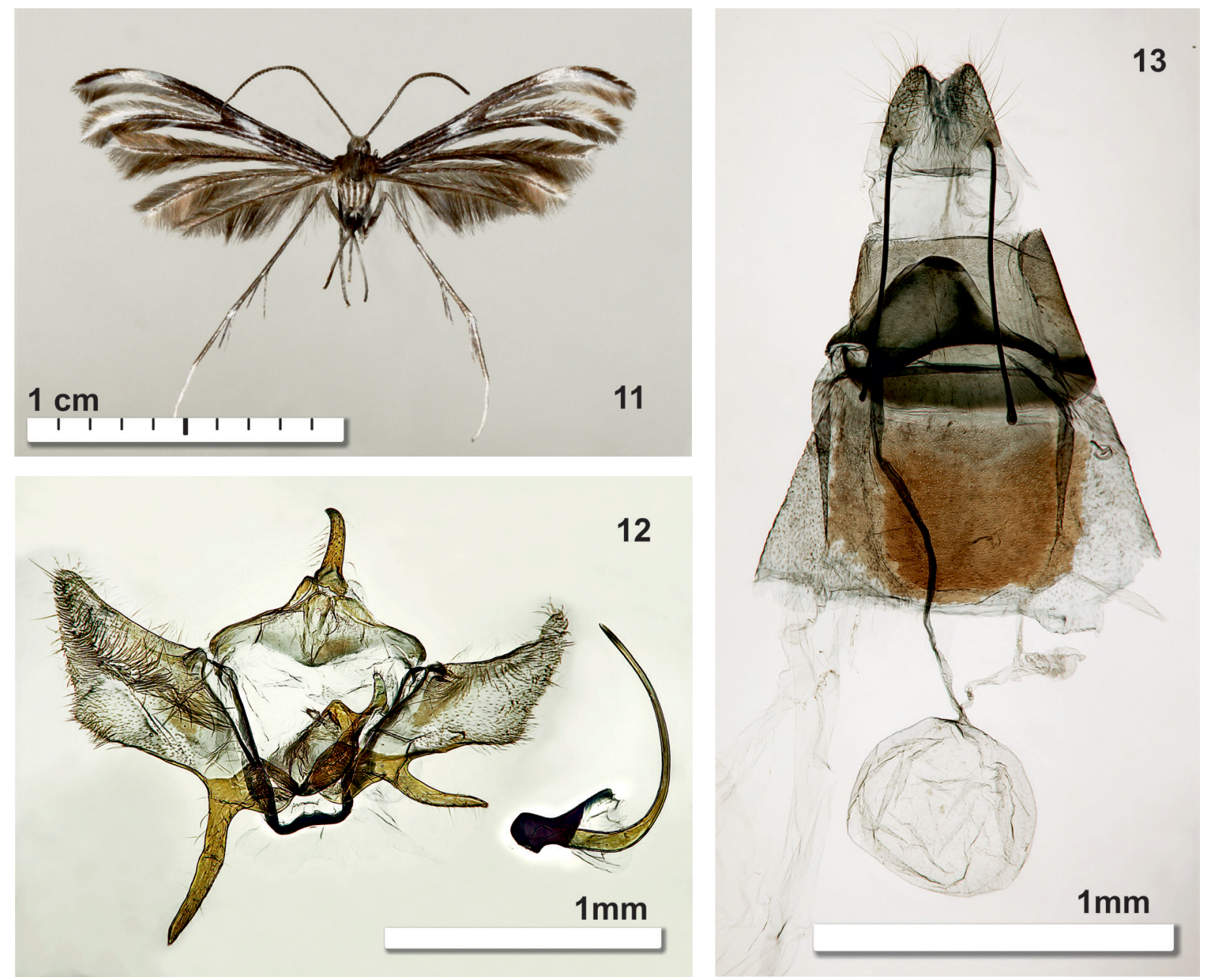

Figs 11-13. Singularia lesya Kovtunovich \& Ustjuzhanin sp. nov. 11. Holotype (ZISP 1840). 12. Holotype, genitalia (ZISP 1840). 13. Paratype,, , genitalia (ZISP 1841). 
Female genitalia. Papillae anales narrow oval. Apophyses posteriores thin, long, slightly thickened at tips. Apophyses anteriores developed. Lamina postvaginalis as a big broad lobe. Antrum short, funnel form. Ductus narrow, long, poorly sclerotized. Ductus seminalis at confluence of ductus into bursa copulatrix. Bursa copulatrix round, without signa.

\section{Distribution}

Ecuador, Colombia.

\section{Flight period}

October-February.

\section{Remarks}

An image of the female of this species was presented in the work of Gielis (2011) as the female of Singularia carabayus. An image of the real S. carabayus female was published in the description of this species by Arenberger (1990).

\section{Discussion}

The rich neotropical fauna of insects, including that of Pterophoridae, is still poorly studied today. Entomological expeditions in recent years have resulted in the discovery of these five Pterophoridae species new to science. Species of Singularia inhabit remote mountain areas of Southern and Central America, and so they are rare in collections. As a result of our study, we now know 12 species of Singularia, and it is possible that this number will significantly increase in the future with further investigations in these hardly accessible areas of Central and South America.

\section{Acknowledgments}

We are sincerely grateful to the organizers of the expeditions - Dr. Ron Brechlin (Pasewalk, Germany) and Viktor Synjaev (Moscow, Russia) and also to the expedition members: Oleg Romanov (Santa Crus, Bolivia) and Juan Machado (La Libertad, Comayagua, Honduras).

\section{References}

Arenberger E. 1990. Zur Kenntnis der neotropischen Pterophorinae (Lepidoptera: Pterophoridae). SHILAP 18: 127-131.

Gielis C. 2011. Review of the Neotropical species of the family Pterophoridae, part II: Pterophorinae (Oidaematophorini, Pterophorini). Zoologische Mededelingen 85: 589-824.

Gielis C. 2012. Review of the Neotropical species of the family Pterophoridae, part III: Additions from Chile, Ecuador and Paraguay (Lepidoptera). Boletin de la Sociedad Entomologica Aragonesa 51: $105-124$.

Gielis C. \& Matthews D. 1994. Neotropical Pterophoridae 9: Chocophorus, a new neotropical genus (Lepidoptera). Entomologische Berichte 54 (9): 161-170.

Manuscript received: 4 February 2016

Manuscript accepted: 8 June 2016

Published on: 29 November 2016

Topic editor: Gavin Broad

Desk editor: Charlotte Gérard 
Printed versions of all papers are also deposited in the libraries of the institutes that are members of the EJT consortium: Muséum national d'Histoire naturelle, Paris, France; Botanic Garden Meise, Belgium; Royal Museum for Central Africa, Tervuren, Belgium; Natural History Museum, London, United Kingdom; Royal Belgian Institute of Natural Sciences, Brussels, Belgium; Natural History Museum of Denmark, Copenhagen, Denmark; Naturalis Biodiversity Center, Leiden, the Netherlands. 